\title{
KLASIFIKASI DATA MINNING MENGGUNAKAN ALGORITMA C4.5 TERHADAP KEPUASAN PELANGGAN SEWA KAMERA CIKARANG
}

\author{
Sutan Faisal \\ sutan.faisal@ubpkarawang.ac.id \\ Universitas Buana Perjuangan Karawang \\ Karawang, Indonesia
}

\begin{abstract}
ABSTRAK
Kepuasan pelanggan merupakan salah satu tujuan dari perusahan dalam memberikan pelayanan kepada pelanggannya baik perusahaan jasa maupun non jasa. Salah satu perusahaan jasa penyedia sewa kamera yang berkomitmen untuk kepuasan pelanggannya adalah Sewa Kamera Cikarang. Penelitian ini bertujuan untuk menganalisa kepuasan pelanggan sewa kamera cikarang dengan menggunakan algoritma K-Nearest Neighbour (KNN). Atribut masukan kepuasan pelanggan dalam penelitian ini mencangkup harga, fasilitas, pelayanan dam loyalitas. Keluaran hasil dari atribut masukan di atas adalah puas dan tidak puas. Penelitian ini diharapkan untuk membantu Sewa Kamera Cikarang untuk meningkatkan kepuasan pelanggan dan meningkatkan laba pada Sewa Kamera Cikarang. Hasil penelitian yang dapat dicapai menggunakan algoritma $C 4.5$ adalah acuracy $=95 \%$, classification recall $=100 \%$, Classification precision $=92.31 \%$ dan $A U C=0.948$. Hasil penelitian ini bisa menjadikan referensi untuk membangun sebuah aplikasi yang dapat memudahkan perusahaan dalam memperoleh informasi mengenai kepuasan pelanggannya.
\end{abstract}

Kata Kunci: Data mining, classification, Algoritma C 4.5, kepuasan pelanggan

\section{PENDAHULUAN}

Untuk mencapai keberhasilan dalam sebuah usaha bidang jasa, kepuasan pelanggan harus menjadi dasar dari keputusan manajemen, sehingga manajemen harus menjadikan peningkatan kepuasan pelanggan sebagai suatu sasaran yang mendasar. Dalam rangka untuk memberikan pelayanan yang berkualitas perusahaan secara continue harus mengadakan peningkatan kualitas SDM dan peralatan yang disewakannya. Langkah ini penting untuk memperbaiki pelayanan dari waktu ke waktu.

Namun perkembangan yang pesat dalam dunia usaha ini mengharuskan perusahaan menghadapi ketatnya persaingan. Pada umumnya banyak cara untuk mempertahankan pelangganya selama-lamanya, didalam persaingan usaha yang sangat ketat ini sangat sulit Untuk mewujudkan hal itu mengingat banyaknya perubahan yang dapat terjadi setiap saat. Seperti perubahan pada diri pelanggan.pesaing maupun perubahan kondisi secara luas yang selalu berubah secara dinamis. Hal ini membuat para pengambil kebijakan untuk terus mengembangkan suatu strategi yang dapat mencapai sasaran pertumbuhan penyewaan, peningkatan porsi pasar , serta pencapaian kemampuan sebagai dasar pertumbuhan berkelanjutan (Tan S, Kumar P, Steinbach M. 2005).

Sementara itu, Data mining adalah proses pengekstrakan informasi dari kumpulan data yang besar (Basuki, Ahmad dan Syarif, Iwan , 2003).. Pengekstrakan informasi dilakukan berdasarkan metode data mining yang akan digunakan. Ada beberapa metode serta algoritma data mining yang digunakan untuk mengekstrak informasi antara lain: metode klasifikasi, metode asosiasi, metode clustering, metode prediksi, dan metode estimasi.

\section{DATA MINING}

Menurut Gartner Group, Bahwa data mining adalah proses menemukan hubungan baru yang mempunyai arti, pola dan kebiasaan dengan memilih sebagian besar data yang disimpan dalam media penyimpanan dengan menggunakan teknologi pengenalan pola seperti Teknik statistic dan matematika. Data mining merupakan gabungan dari beberapa disiplin ilmu yang menyatukan teknik dari pembelajaran mesin, pengenalan pola, statistik, database, dan isualisasi untuk penanganan permasalahan pengambilan informasi dari database yang besar [1]

Data mining menurut David Hand, Heikki Mannila, dan Padhraic Smyth dari MIT adalah analisa terhadap data mining (big data) untuk menemukan hubungan yang jelas serta menyimpulkannya yang belum diketahui sebelumnya dengan cara terkini di pahami dan berguna bagi pemilik data tersebut[2]. Data mining adalah proses yang menggunakan teknik statistik, 
matematika, kecerdasan buatan, dan machine learning untuk mengekstraksi dan mengidentifikasi informasi yang bermanfaat dan pengetahuan yang terkait dari berbagai database besar. Data mining merupakan serangkaian proses untuk menggali nilai tambah dari suatu kumpulan data berupa pengetahuan yang selama ini tidak diketahui secara manual [2].

Jadi data mining dapat diartikan sebagai berikut:

1. Data mining merupakan suatu proses otomatis untuk menganalisa data.

2. Data yang akan diproses merupakan data yang sangat besar, sehingga sulit untuk menproses dengan manual

3. Tujuan data mining adalah mendapatkan hubungan atau pola/ Teknik yang memberikan indikasi yang bermanfaat.

Data mining bukanlah hal yang baru, satu kesulitan untuk mendefinisikan data mining adalah kenyataan bahwa data mining mewarisi banyak aspek dan teknik dari bidang-bidang ilmu yang dulu sudah mapan terlebih dulu. data mining memiliki akar yang Panjang dari bidang ilmu yang berbeda seperti kecerdasan buatan (artificial ntelligent), machine learning, statistik, database, dan juga information retrieval [2]

Database yang tersimpan di media penyimpanan jarang sekali dimanfaatkan oleh sebagian besar penggunanya dan bahkan dalam jangka waktu tertentu data-data tersebut dihapus karena dianggap sampah dan hanya memenuhi media penyimpanan saja. Anggapan tersebut tidak sepenuhnya benar, karena sesungguhnya database dalam ukuran yang besar dapat memberikan informasi yang dibutuhkan untuk berbagai kepentingan, baik untuk kepentingan bisnis dalam mengambil keputusan maupun untuk ilmu pengetahuan dan penelitian.

\section{CLASSIFICATION}

Salah satu tugas yang dapat dilakukan dengan data mining adalah pengklasifikasian. Klasifikasi pertama kali diterapkan pada bidang tanaman yang mengklasifikasi suatu spesies tertentu, seperti yang dilakukan oleh Carolus von Linne (atau dikenal dengan nama Carolus Linnaeus) yang pertama kali mengklasifikasi spesies berdasarkan karakteristik fisik. Selanjutnya dia dikenal sebagai bapak klasifikasi [3].

Dalam klasifikasi terdapat target variable kategori. Metode-metode / model-model yang telah dikembangkan oleh periset untuk menyelesaikan kasus klasifikasi antara lain Pohon keputusan, Jaringan saraf tiruan. Dll.

Operator ini digunakan untuk evaluasi kinerja statistik dari tugas klasifikasi binominal yaitu tugas klasifikasi dimana atribut label memiliki tipe binominal. Operator ini memberikan daftar nilai kriteria kinerja dari tugas klasifikasi binominal.

Operator ini harus digunakan secara khusus untuk evaluasi kinerja hanya tugas klasifikasi binominal yaitu tugas klasifikasi dimana atribut label memiliki tipe binominal. Banyak operator evaluasi kinerja lainnya juga tersedia di RapidMiner misalnya. operator Kinerja, operator Kinerja (Klasifikasi), operator Kinerja (Regresi), dan lain-lain. Operator Kinerja (Binominal Klasifikasi) digunakan hanya dengan tugas klasifikasi binominal saja. Di sisi lain, operator Kinerja secara otomatis menentukan jenis tugas pembelajaran dan menghitung kriteria yang paling umum untuk tipe itu. Anda dapat menggunakan operator Performance (User-Based) jika Anda ingin menulis ukuran kinerja Anda sendiri.

\section{DECISION TREE}

Pohon keputusan adalah salah satu metode klasifikasi yang paling populer karena mudah untukdiinterpretasi oleh manusia. Pohon keputusan adalah model prediksi menggunakan struktur pohon ataustruktur berhirarki. Konsep dari pohon keputusan adalah mengubah data menjadi pohon keputusan danaturan-aturan keputusan.

Manfaat utama dari penggunaan pohon keputusan adalah kemampuannya untukmem-break down proses pengambilan keputusan yang kompleks menjadi lebih simpel sehinggapengambil keputusan akan lebih menginterpretasikan solusi dari permasalahan. Pohon Keputusan jugaberguna untuk mengeksplorasi data, menemukan hubungan tersembunyi.

Decision tree (pohon keputusan)adalah sebuah diagram alir yang mirip dengan struktur pohon, dimana setiap internal node menotasikanatribut yang diuji, setiap cabangnya merepresentasikan hasil dari atribut tes tersebut, dan leaf node merepresentasikan kelas-kelas tertentu atau distribusi dari kelas-kelas (Han J, Kamber M, 2001).

Klasifier pohon keputusan merupakan teknik klasifikasi yang sederhana yang banyak digunakan.Bagian ini membahas bagaimana pohon keputusan bekerja dan bagaimana pohon keputusan dibangun.Seringkali untuk mengklasifikasikan obyek, kita ajukan urutan pertanyaansebelum bisa kita tentukankelompoknya. 


\section{ALGORITMA C 4.5}

Algoritma C4.5 adalah salah satu algoritma untuk mengubah fakta yang besar menjadi pohon keputusan (decision tree) yang merepresentasikan aturan (rule). Tujuan dari pembentukan pohon keputusan dalam algoritma $\mathrm{C} 4.5$ adalah untuk mempermudah dalam penyelesaian permasalahan.

Dalam menggunakan algoritma C4.5 terdapat beberapa tahapan yang umum yaitu pertama mengubahbentuk data dalam tabel menjadi model pohon kemudian mengubah model pohon menjadi aturan (rule) dan terakhir menyederhanakan rule (Basuki, Ahmad dan Syarif, Iwan , 2003).

Secara umum, algoritma C4.5 untuk membangun sebuah pohon keputusan adalah sebagai berikut:

a. Hitung jumlah data, jumlah data berdasarkan anggota atribut hasil dengan syarat tertentu. Untukproses pertama syaratnya masih kosong.

b. Pilih atribut sebagai Node.

c. Buat cabang untuk tiap-tiap anggota dari Node.

d. Periksa apakah nilai entropy dari anggota Node ada yang bernilai nol. Jika ada, tentukan daunyang terbentuk. Jika seluruh nilai entropy anggota Node adalah nol, maka proses pun berhenti.

e. Jika ada anggota Node yang memiliki nilai entropy lebih besar dari nol, ulangi lagi proses dariawal dengan Node sebagai syarat sampai semua anggota dari Node bernilai nol. Node adalah atribut yang mempunyai nilai gain tertinggi dari atribut-aribut yang ada. Untuk menghitung nilai gain suatu atribut digunakan rumus seperti yang tertera dalam persamaan berikut:

$$
\operatorname{Gain}(\mathrm{S}, \mathrm{A})=\operatorname{Entropy}(\mathrm{S})-\sum_{\mathrm{i}=1}^{\mathrm{n}}\left|\frac{\mathrm{S}_{\mathrm{i}}}{\mathrm{S}}\right| \times \operatorname{Entropy}\left(\mathrm{S}_{\mathrm{i}}\right)
$$

Keterangan:

S:himpunan kasus

A : atribut

$\mathrm{n}$ : jumlah partisi atribut $\mathrm{A}$

|Si| : jumlah kasus pada partisi ke-i

$|S|$ : jumlah kasus dalam $S$

penghitungan nilai entropi dapat dilihat pada persamaan berikut (kusrini, Emha Taufiq Lut :2009).

Keterangan:

$$
\operatorname{Entropy}(\mathrm{S})=\sum_{\mathrm{i}=1}^{\mathrm{n}}-p_{i} \times \log _{2} p_{i}
$$

S:himpunan kasus

A : fitur
$\mathrm{n}:$ jumlah partisi $S$
pi : proporsi dari Si terhadap $S$

\section{METHODOLOGY}

Pada penelitian ini menggunakan tools pengujian rapidminer studio 9.0, dengan mengunakan methodology sebagai berikut:

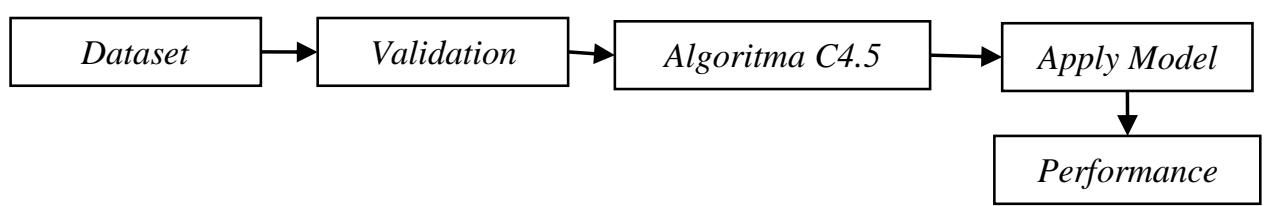

Gambar 1. Methodology yang digunakan

\subsection{Dataset}

Dataset merupakan kumpulan data, yang mana biasanya satu dataset merepresentasikan satu tabel database, atau bisa juga suatu matriks data yang mana tiap kolom mewakili variabel tertentu, tiap baris mereprentasikan banyaknya data.

Dalam penelitian ini menggunakan Operator Retrieve memuat Objek RapidMiner ke dalam Proses. Objek ini berupa ExampleSet namun bisa juga berupa Collection atau Model. Mengambil data dengan cara ini juga menyediakan data meta dari RapidMiner Object. 


\subsection{Validation}

Validation sebagai Operator untuk melakukan validasi sederhana yaitu secara acak membagi ExampleSet menjadi satu set pelatihan dan menetapkan tes dan mengevaluasi modelnya. Operator ini melakukan validasi split untuk memperkirakan kinerja operator pembelajaran (biasanya pada kumpulan data yang tidak terlihat). Hal ini terutama digunakan untuk memperkirakan seberapa akurat sebuah model (dipelajari oleh operator pembelajaran tertentu) akan tampil dalam praktik.

\subsection{Algoritma C 4.5}

Dalam penelitian ini dilakukan eksperimen menggunakan metode klasifikasi data mining decisision tree algoritma C 4.5 terhadap data kuisioner kepuasan pelanggan pada Sewa Kamera Cikarang. Data akan diolah dengan menggunakan algoritma C4.5 dan menghasilkan model, maka terhadap model yang dihasilkan tersebut dilakukan pengujian Cross Validation yang menhasilkan accuracy, precision, recall dan AUC.

\subsection{Apply Model}

Apply Model adalah suatu model pertama dilatih pada ExampleSet oleh Operator lain, yang sering merupakan algoritma pembelajaran. Setelah itu, model ini bisa diaplikasikan pada ExampleSet yang lain. Biasanya, tujuannya adalah untuk mendapatkan prediksi pada data yang tidak terlihat atau untuk mentransformasikan data dengan menerapkan model preprocessing.

ExampleSet dimana model diterapkan, harus kompatibel dengan Atribut model. Ini berarti, bahwa ExampleSet memiliki jumlah, urutan, jenis, dan peran Atribut yang sama seperti ExampleSet yang digunakan untuk menghasilkan model.

\subsection{Performance}

Operator ini digunakan untuk evaluasi kinerja statistik dari tugas klasifikasi binominal yaitu tugas klasifikasi dimana atribut label memiliki tipe binominal. Operator ini memberikan daftar nilai kriteria kinerja dari tugas klasifikasi binominal.

Untuk mengukur hasil penelitian ini dengan menggunakan confusion matrix (accuracy, Classification recall, Classification precition) dan kurva ROC.

\section{HASIL DAN PEMBAHASAN}

7.1. Hasil Analisis Data Set

Dataset yang digunakan adalah dataset kuisioner kepuasan pelanggan Sewa Kamera Cikarang, dataset ini berisi data - data informasi tentang kuisioner kepuasan pelanggan mengenai harga, fasilitas, pelayanan dan loyalitas. Keseluruhan data pada dataset ini berjumlah 100 records yang setiap record nya memiliki 10 atribut diantaranya :

1. No (integer, role : id)

2. Nama (polynominal)

3. Harga X1 (integer)

4. Fasilitas X2 (integer)

5. Pelayanan X3 (integer)

6. Loyalitas X4 (integer)

7. Hasil (binomial : puas \& tidak puas)

8. Confidence tidak puas (real)

9. Confidence puas (real)

10. Prediksi hasil (binomial)

Dari atribut dataset di atas (1 sampai 10) akan dilakukan proses training dan test menggunakan metode deep learning, sedangkan atribut ke - 10 akan menjadi target hasil dari proses klasifikasi. dan di sini kami akan mencoba menganalisis perbedaan dari akurasi dan eror yang didapat dengan membandingka prediksi hasil dan hasil. 
Kuisioner dapat digambarkan di bawah ini

KUISIONER PENELITIAN
KEPUASAN PELANGGAN TERHADAP SEWA KAMERA CIKARANG

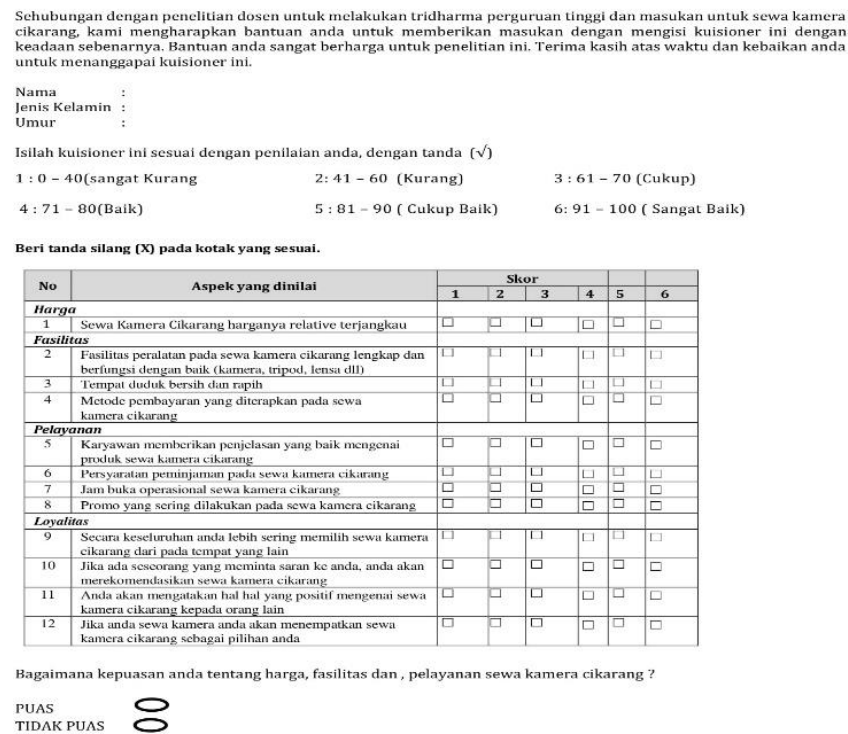

Gambar 2 Form Kuisioner Data kuisioner yang telah diolah menggunakan MS Excel

\begin{tabular}{|c|c|c|c|c|c|c|c|c|c|c|c|c|c|c|c|c|c|c|c|}
\hline \multirow[t]{2}{*}{ No } & \multirow[t]{2}{*}{ Namn } & \multirow[t]{2}{*}{$\begin{array}{l}\text { Jenis } \\
\text { Kelamin } \\
(L / P)\end{array}$} & \multirow[t]{2}{*}{$\begin{array}{l}\mathrm{Xl}= \\
\text { harga } 1\end{array}$} & \multirow[t]{2}{*}{$\begin{array}{l}\text { Rata } \\
\text { Rata X1 }\end{array}$} & \multicolumn{3}{|c|}{$\begin{array}{c}\mathrm{X} 2= \\
\text { fasilitas }\end{array}$} & \multirow[t]{2}{*}{ Rata-Rata X2 } & \multicolumn{4}{|c|}{$\begin{array}{c}\mathrm{X} 3= \\
\text { pelayamn }\end{array}$} & \multirow[t]{2}{*}{ Rata-RataX3 } & \multicolumn{4}{|c|}{$\begin{array}{c}\mathrm{X} 4= \\
\text { loyalitas }\end{array}$} & \multirow[t]{2}{*}{ Rata-RataX4 } & \multirow[t]{2}{*}{ Hasil } \\
\hline & & & & & 2 & 3 & 4 & & 5 & 6 & 7 & 8 & & 9 & 10 & 11 & 12 & & \\
\hline 1 & Dian & $\mathrm{P}$ & 5 & 5 & 2 & 3 & 3 & 2.67 & 3 & 4 & 3 & 4 & 3.5 & \begin{tabular}{l|l}
4 \\
\end{tabular} & 3 & 3 & 3 & 3.25 & IIDAK PUAS \\
\hline 2 & Wiwin & $\mathrm{L}$ & 5 & 5 & 5 & 3 & 4 & 4.00 & 4 & 4 & 4 & 4 & 4 & 4 & 4 & 3 & 5 & 4 & PUAS \\
\hline 3 & Iw an & $\mathrm{L}$ & 5 & 5 & 5 & 3 & 4 & 4.00 & 4 & 4 & 4 & 4 & 4 & 4 & 4 & 3 & 4 & 3.75 & PUAS \\
\hline 4 & Antan & $\mathrm{L}$ & 3 & 3 & 4 & 3 & 3 & 3.33 & 4 & 2 & 2 & 4 & 3 & 4 & 2 & 2 & 3 & 2.75 & IIDAK PUAS \\
\hline 5 & Taufik & $\mathrm{L}$ & 5 & 5 & 4 & 3 & 4 & 3.67 & 4 & 3 & 4 & 4 & 3.75 & 4 & 4 & 4 & 4 & 4 & PUAS \\
\hline 6 & Doni & $\mathrm{L}$ & 3 & 3 & 4 & 3 & 4 & 3.67 & 4 & 3 & 4 & 5 & 4 & 4 & 4 & 4 & 4 & 4 & PUAS \\
\hline 7 & Didi & $\mathrm{L}$ & 4 & 4 & 3 & 2 & 4 & 3.00 & 4 & 2 & 2 & 3 & 2.75 & 3 & 2 & 2 & 4 & 2.75 & IIDAK PUAS \\
\hline 8 & Adi & $\mathrm{L}$ & 5 & 5 & 5 & 4 & 4 & 4.33 & 4 & 3 & 4 & 5 & 4 & 4 & 3 & 4 & 4 & 3.75 & PUAS \\
\hline 9 & Joko & $\mathrm{L}$ & 6 & 6 & 5 & 4 & 5 & 4.67 & 4 & 3 & 4 & 5 & 4 & 4 & 3 & 4 & 4 & 3.75 & PUAS \\
\hline 10 & Gina & $P$ & 5 & 5 & 5 & 4 & 5 & 4.67 & 4 & 3 & 4 & 5 & 4 & 4 & 3 & 4 & 3 & 3.5 & PUAS \\
\hline 11 & Ahmad & $\mathrm{L}$ & 3 & 3 & 4 & 4 & 3 & 3.67 & 4 & 2 & 2 & 5 & 3.25 & 4 & 2 & 2 & 3 & 2.75 & IIDAK PUAS \\
\hline 12 & Yanto & $\mathrm{L}$ & 5 & 5 & 4 & 3 & 5 & 4.00 & 4 & 3 & 4 & 3 & 3.5 & 4 & 3 & 4 & 3 & 3.5 & PUAS \\
\hline 13 & Fifi & $P$ & 3 & 3 & 4 & 2 & 3 & 3.00 & 4 & 2 & 2 & 3 & 2.75 & 4 & 2 & 2 & 3 & 2.75 & IIDAK PUAS \\
\hline 14 & Fila & $P$ & 3 & 3 & 4 & 3 & 4 & 3.67 & 3 & 2 & 2 & 3 & 2.5 & 3 & 2 & 2 & 3 & 2.5 & IIDAK PUAS \\
\hline 15 & Rendi & $\mathrm{L}$ & 6 & 6 & 4 & 3 & 4 & 3.67 & 5 & 2 & 3 & 3 & 3.25 & 4 & 4 & 3 & 4 & 3.75 & PUAS \\
\hline 16 & Dede & $\mathrm{L}$ & 4 & 4 & 4 & 4 & 4 & 4.00 & 5 & 2 & 3 & 3 & 3.25 & 5 & 4 & 3 & 4 & 4 & PUAS \\
\hline 17 & Santi & $\mathrm{P}$ & 3 & 3 & 3 & 4 & 3 & 3.33 & 5 & 2 & 2 & 4 & 3.25 & 5 & 4 & 3 & 4 & 4 & IIDAK PUAS \\
\hline 18 & Deden & $\mathrm{L}$ & 5 & 5 & 5 & 4 & 5 & 4.67 & 6 & 3 & 3 & 4 & 4 & 5 & 4 & 3 & 4 & 4 & PUAS \\
\hline 19 & Jamilah & $P$ & 2 & 2 & 5 & 5 & 5 & 5.00 & 3 & 3 & 4 & 4 & 3.5 & 6 & 4 & 4 & 6 & 5 & PUAS \\
\hline 20 & Fayzan & $\mathrm{L}$ & 3 & 3 & 3 & 3 & 3 & 3.00 & 4 & 2 & 3 & 4 & 3.25 & 3 & 2 & 2 & 4 & 2.75 & IIDAK PUAS \\
\hline 21 & Vina & $P$ & 3 & 3 & 3 & 4 & 3 & 3.33 & 3 & 2 & 2 & 4 & 2.75 & \begin{tabular}{|l|l}
3 \\
\end{tabular} & 2 & 2 & 4 & 2.75 & IIDAK PUAS \\
\hline 22 & Lukman & $\mathrm{L}$ & 5 & 5 & 5 & 2 & 3 & 3.33 & \begin{tabular}{l|l}
4 \\
\end{tabular} & 2 & 4 & 4 & 3.5 & 3 & 5 & 4 & 4 & 4 & PUAS \\
\hline 23 & Bayo & $\mathrm{L}$ & 5 & 5 & 6 & 4 & 3 & 4.33 & \begin{tabular}{l|l}
4 \\
\end{tabular} & 4 & 4 & 6 & 4.5 & 3 & 4 & 3 & 4 & 3.5 & PUAS \\
\hline 24 & Antik & L & 5 & 5 & 6 & 4 & 4 & 4.67 & \begin{tabular}{l|l}
4 \\
\end{tabular} & \begin{tabular}{l|l}
4 \\
\end{tabular} & 4 & \begin{tabular}{|l|}
4 \\
\end{tabular} & 4 & \begin{tabular}{|l|l|}
3 & \\
\end{tabular} & 4 & 3 & 4 & 3.5 & PUAS \\
\hline
\end{tabular}

Gambar 3 Data kuisioner yang telah diolah 
Data kuisioner yang telah diolah lagi

\begin{tabular}{|c|c|c|c|c|c|c|}
\hline No & Nama & Harga X1 & Fasilitas X2 & Pelayanan X3 & Loyalitas X4 & Hasil \\
\hline 1 & Dian & 5 & 2.67 & 3.50 & 3.25 & $\begin{array}{l}\text { TIDAK } \\
\text { PUAS }\end{array}$ \\
\hline 2 & Wiwin & 5 & 4.00 & 4.00 & 4.00 & PUAS \\
\hline 3 & Iwan & 5 & 4.00 & 4.00 & 3.75 & PUAS \\
\hline 4 & Anton & 3 & 3.33 & 3.00 & 2.75 & $\begin{array}{l}\text { TIDAK } \\
\text { PUAS }\end{array}$ \\
\hline 5 & Taufik & 5 & 3.67 & 3.75 & 4.00 & PUAS \\
\hline 6 & Doni & 3 & 3.67 & 4.00 & 4.00 & PUAS \\
\hline 7 & Didi & 4 & 3.00 & 2.75 & 2.75 & $\begin{array}{l}\text { TIDAK } \\
\text { PUAS }\end{array}$ \\
\hline 8 & Adi & 5 & 4.33 & 4.00 & 3.75 & PUAS \\
\hline 9 & Joko & 6 & 4.67 & 4.00 & 3.75 & PUAS \\
\hline 10 & Gina & 5 & 4.67 & 4.00 & 3.50 & PUAS \\
\hline 11 & Ahmad & 3 & 3.67 & 3.25 & 2.75 & $\begin{array}{l}\text { TIDAK } \\
\text { PUAS }\end{array}$ \\
\hline 12 & Yanto & 5 & 4.00 & 3.50 & 3.50 & PUAS \\
\hline 13 & Fifi & 3 & 3.00 & 2.75 & 2.75 & $\begin{array}{l}\text { TIDAK } \\
\text { PUAS }\end{array}$ \\
\hline 14 & Fika & 3 & 3.67 & 2.50 & 2.50 & $\begin{array}{l}\text { TIDAK } \\
\text { PUAS }\end{array}$ \\
\hline 15 & Rendi & 6 & 3.67 & 3.25 & 3.75 & PUAS \\
\hline 16 & Dede & 4 & 4.00 & 3.25 & 4.00 & PUAS \\
\hline 17 & Santi & 3 & 3.33 & 3.25 & 4.00 & $\begin{array}{l}\text { TIDAK } \\
\text { PUAS }\end{array}$ \\
\hline 18 & Deden & 5 & 4.67 & 4.00 & 4.00 & PUAS \\
\hline 19 & Jamilah & 2 & 5.00 & 3.50 & 5.00 & PUAS \\
\hline 20 & Fauzan & 3 & 3.00 & 3.25 & 2.75 & $\begin{array}{c}\text { TIDAK } \\
\text { PUAS }\end{array}$ \\
\hline 21 & Vina & 3 & 3.33 & 2.75 & 2.75 & $\begin{array}{l}\text { TIDAK } \\
\text { PUAS }\end{array}$ \\
\hline 22 & Lukman & 5 & 3.33 & 3.50 & 4.00 & PUAS \\
\hline 23 & Bayu & 5 & 4.33 & 4.50 & 3.50 & PUAS \\
\hline 24 & Antik & 5 & 4.67 & 4.00 & 3.50 & PUAS \\
\hline
\end{tabular}

Gambar Data kuisioner yang telah diolah lagi

7.2. Hasil Percobaan dan Evaluasi

Pada percobaan ini terdapat 10 atribut yang akan di training dan 2 nilai yang menunjukan target (klasifikasi) pada atribut ke - 10 yang berarti pada algoritma C4.5 diinisialisasi kan 9 atribut input dan 1 atribut output.

Hasil dari penelitian ini adalah :

1. Tabel Confusion Matrix

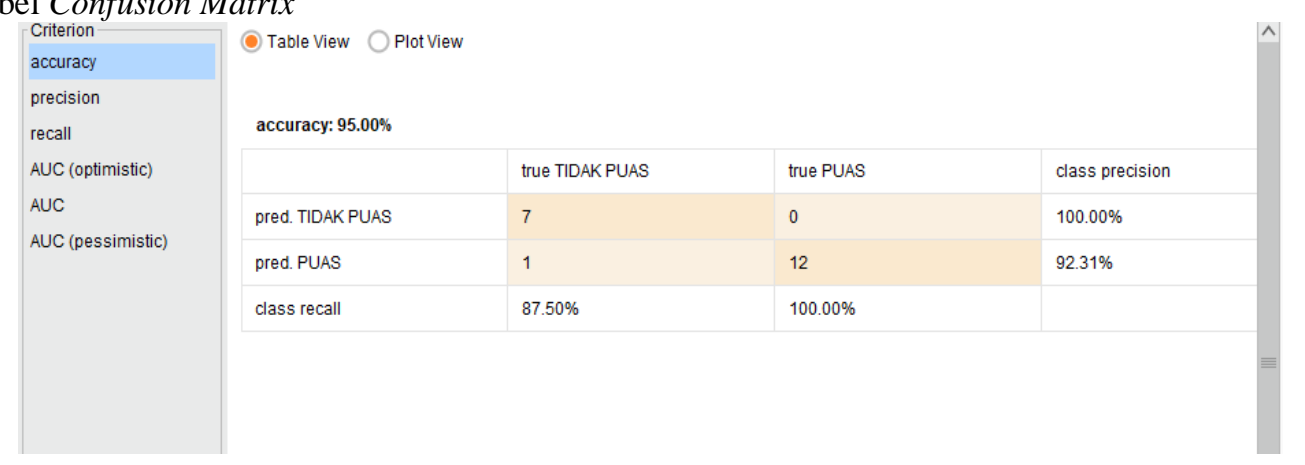




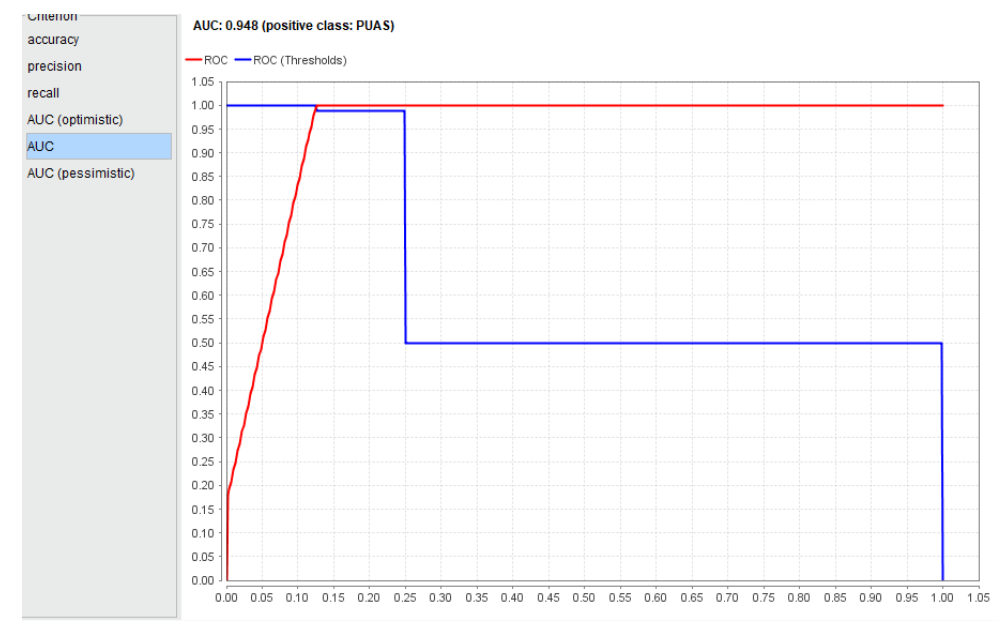

2. Pervormance Vector

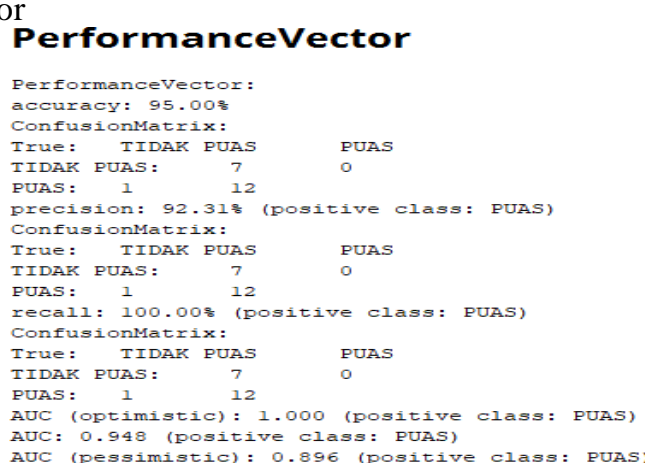

\section{KESIMPULAN DAN SARAN}

8.1. Kesimpulan

Metode klasifikasi dengan menggunakan algoritma C 4.5 sangat baik untuk menentukan kebenaran dari klasifikasi dalam data mining. Terbukti dengan hasil acuracy $=95 \%$, Classification recall $=100 \%$, Classification precision $=92.31 \%$ dan $\mathrm{AUC}=0.948$.

\subsection{Saran}

Dari hasil pengujian yang telah dilakukan dan hasil kesimpulan yang didapatkan maka ada saran yang diberikan :

1. Untuk penelitian selanjutnya bisa digunakan algoritma yang lain

2. Hasil penelitian ini bisa digunakan untuk keperluan perusahaan dalam memprediksi kepuasan pelanggannya.

\section{Daftar Pustaka}

[1] Barber, I. "Bayesian Opinion Mining." Tersedia di: http://phpir. com/bayesianopinion- mining [diunduh: 10 Nov 2010] (2010).

[2] Bramer, Max. Principles of data mining. Vol. 180. London: Springer, 2007.

[3] Basuki, Achmad dan Syarif, Iwan. 2003. Modul Ajar Decision tree. Surabaya : PENS-ITS.

[4] Giudici, Paolo, and Silvia Figini. Front Matter. John Wiley \& Sons, Ltd, 2009.Applied Data mining for Business and Industry

[5] Gorunescu, Florin. Data mining: Concepts, models and techniques. Vol. 12. Springer Science \& Business Media, 2011.

[6] Han J, Kamber M. 2001. Data mining : Concepts and Techniques. Simon Fraser University, Morgan Kaufmann Publishers.

[7] Larose, D.T, 2006. Discovering Knowledge in Data: An Introduction to Data mining. John Willey \&Sons, Inc.

[8] Maimon, Oded, and Lior Rokach, eds. Data mining and knowledge discovery handbook. Vol. 2. New York: Springer, 2005.

[9] Powers, David Martin. "Evaluation: from precision, recall and F-measure to ROC, informedness, markedness and correlation." (2011).

[10] Rapid-I GmbH. (2008).Rapidminer-4.2-tutorial. Germany: Rapid-I. 
[11] Sachdeva, M., Zhu, S., Wu, F., Wu, H., Walia, V., Kumar, S., ... \& Mo, Y. Y. (2009). p53 represses c-Myc through induction of the tumor suppressor miR-145. Proceedings of the National Academy of Sciences, 106(9), 3207-3212.

[12] Santosa, Budi. 2007. Data mining : Teknik Pemanfaatan Data untuk Keperluan Bisnis, Teori dan Aplikasi. Graha Ilmu Yogyakarta

[13] Tan S, Kumar P, Steinbach M. 2005. Introduction To Data mining. Addison Wesley.

[14] Vitaro, F., Brendgen, M., Larose, S., \& Trembaly, R. E. (2005). Kindergarten Disruptive Behaviors, Protective Factors, and Educational Achievement by Early Adulthood. Journal of educational psychology, 97(4), 617.

[15] M Rizki Ilham, Purwanto. 2016. Implementasi Data mining Menggunakan Algoritma C 4.5 Untuk Prediksi Kepuasan Pelanggan. UDINUS Semarang 